\title{
RECOVERY OF RESCUERS FROM A 24-H SHIFT AND ITS ASSOCIATION WITH AEROBIC FITNESS
}

\section{KATARIINA LYYTIKÄINEN ${ }^{1}$, LEENA TOIVONEN ${ }^{2}$, ESA HYNYNEN ${ }^{3}$, HARRI LINDHOLM ${ }^{4}$, and HEIKKI KYRÖLÄINEN ${ }^{1}$}

${ }^{1}$ University of Jyväskylä, Jyväskylä, Finland

Faculty of Sport and Health Sciences, Department of Biology of Physical Activity

${ }^{2}$ Occupational Health Care Aalto, Jyväskylä, Finland

${ }^{3}$ Research Institute for Olympic Sports, Jyväskylä, Finland

${ }^{4}$ Finnish Institute of Occupational Health, Helsinki, Finland

\begin{abstract}
Objectives: Rescuers work in 24-h shifts and the demanding nature of the occupation requires adequate recovery between work shifts. The purpose of this study has been to find out what kind of changes in autonomic control may be seen during work shift and its recovery period in the case of rescuers. An additional interest has been to see if aerobic fitness is associated with recovery from work shifts. Material and Methods: Fourteen male rescuers (aged $34 \pm 9$ years old) volunteered to participate in the study. Heart rate variability (HRV) was recorded for $96 \mathrm{~h}$ to study stress and recovery, from the beginning of a 24-h work shift to the beginning of the next shift. Aerobic fitness assessment included maximal oxygen uptake $\left(\mathrm{VO}_{2 \max }\right)$ estimation with a submaximal bicycle ergometer test. Salivary cortisol samples were collected $0 \mathrm{~min}, 15 \mathrm{~min}$, and $30 \mathrm{~min}$ after awakening on the 3 resting days. Results: Some HRV parameters showed enhanced autonomic control after the work shift. Stress percentage decreased from the working day to the 2nd rest day $(\mathrm{p}<0.05)$. However, maximal oxygen uptake was not associated with enhanced parasympathetic cardiac control $(\mathrm{p}>0.05)$. Cortisol awakening response was attenuated right after the work shift. Conclusions: The HRV findings show that recovery after a long work shift takes several days. Thus, rescuers should pay attention to sufficient recovery before the next work shift, and an integrated model of perceived and physiological measurements could be beneficial to assess cardiovascular strain among rescuers with long work shifts. Int J Occup Med Environ Health 2017;30(3):433-444
\end{abstract}

Key words:

Recovery, Stress, Heart rate variability, Firefighters, Aerobic fitness, Cortisol awakening response

\section{INTRODUCTION}

Firefighters and rescuers have a highly demanding occupation, where they might be under heavy stress on a regular basis. They have to perform physically demanding tasks but also have to face many psychologically challenging situations during their rescue. Recently,
Punakallio et al. [1] have reported that $1 / 4$ of the Finnish firefighters belong to the diminished work ability trajectory during 13-year follow-up, and high mental stress is associated with decreased work ability. Unhealthy lifestyle factors have a negative impact on work-related fitness in the same population [2].

Received: June 25, 2015. Accepted: April 26, 2016.

Corresponding author: K. Lyytikäinen, University of Jyväskylä, Faculty of Sport and Health Sciences, Department of Biology of Physical Activity, Meripoiju 3F 51, 02320 Espoo, Finland (e-mail: k.lyytikainen@hotmail.com). 
Recently, the importance of recovery from work-related strain has been acknowledged. A good balance between activation and rest is crucial for health and survival. The inability to rest and recover from work demands may have severe consequences [3,4]. Prolonged working shifts and working at night challenge the rhythmicity of many physiologic systems such as sleep, alertness, performance, metabolism and hormone (e.g., melatonin and cortisol) secretions. Shift work is also associated with decrements in workplace performance, health, and safety. Furthermore, cardiovascular disease, increased accident risk, disturbed sleep and increased fatigue are all associated with shift work [5-8].

Lusa et al. [9] studied work stress and recovery in rescue workers during a 24-h shift. They found that the physical strain of work did not exceed the individual capacity for well-trained men. In the whole group, the autonomic nervous system (ANS) function and recovery were sufficient. There were, however, some peaks in physical loading during fire suppression activities (78\% of maximal oxygen uptake $-\mathrm{VO}_{2 \max }$ ) which led to delayed recovery [9]. Although many studies conclude that firefighting has extreme physical requirements, Bos et al. [10] have reported that the energetic intensity is moderate during actual firefighting. However, the peak loads may be very high in energetic requirements and may lead to excessive fatigue.

Heat load increases the circulatory strain, and the heart rates during real-life fire suppression are higher than measured oxygen consumption predicts [11,12]. Many studies have measured only live-fire simulated firefighting drills, which means that the overall strain of the work shift is not taken into account. During a 24-h shift firefighters have time to rest between alarms and, according to Bos et al. [10], this rest is most likely adequate for recovery. There is, however, limited information about long-term dynamic changes during various rescue work tasks and recovery.

The measurement of the autonomic nervous system using heart rate variability (HRV) and assessment of serum and/ or saliva hormonal concentrations are two common methods used for studying physiological responses to stress. Heart rate variability is generally accepted as an estimate of the autonomic, especially parasympathetic, control of the heart [1316]. When stress is present, HRV may be used for detecting changes in ANS very rapidly, whereas hormonal changes may take hours or days to be observed [17]. Decreases in HRV have been found in athletes during hard training periods as well as during physically demanding periods in occupational work [14]. Heart rate variability measurements and salivary cortisol responses have been used in this study for revealing stress and recovery processes in the body.

The human heart, ANS and HRV responses are affected by both psychological and physiological stimuli. It is generally agreed that heart rate increases due to both a parasympathetic withdrawal and an increased sympathetic activity during dynamic exercise [13,18]. It has been proposed that long-term endurance training affects the autonomic nervous system by increasing parasympathetic activity and decreasing sympathetic activity in the human heart at rest $[13,19]$. Therefore, the purpose of this study has been to find answers to the following questions:

1. What kind of changes in HRV may be seen between a 24-h shift and 3 rest days for rescue workers?

2. Does aerobic fitness associate with recovery from work shifts for rescue workers?

It has been hypothesized that overall HRV increases after the work shift when rescuers have time to recover. In addition, it has been hypothesized that better aerobic fitness enhances recovery processes for rescuers by increasing parasympathetic and decreasing sympathetic influences on the heart.

\section{MATERIAL AND METHODS}

\section{Subjects}

Fourteen male rescuers (aged $34 \pm 9$ years old, body height $178 \pm 7 \mathrm{~cm}$, body mass $80.8 \pm 11.4 \mathrm{~kg}, \mathrm{VO}_{2 \max } 51 \pm 9 \mathrm{ml} / \mathrm{kg} / \mathrm{min}$ ) from the Central Finland Fire Department volunteered to participate in the study. All rescuers did a similar type of work, 
including $12 \mathrm{~h}$ of firefighting and $12 \mathrm{~h}$ of paramedic work during one shift. The study plan was introduced to the subjects and a written consent had been obtained prior to measurements. Thereafter, the subjects filled out a health questionnaire to establish possible contraindications for physical tests. None of the subjects was taking medications that affected the function of the autonomic nervous system.

\section{Anthropometrics}

Body height, weight, and composition of the subjects were measured before other tests. Body composition was measured by using a bioelectrical impedance analysis (InBody 3.0, Biospace Co., Seoul, Korea). All anthropometrical data was collected in the laboratories in the Department of Biology of Physical Activity at the University of Jyväskylä, Finland.

\section{Submaximal bicycle ergometer test}

The World Health Organization (WHO) submaximal bicycle ergometer test was performed a couple weeks before the 24-h work shift. The test was used for estimating subjects' $\mathrm{VO}_{2 \max }$ [20]. The tests were performed in a testing laboratory in the Department of Biology of Physical Activity at the University of Jyväskylä, Finland. Before starting the graded exercise test, the procedure had been explained. Heart rate (HR) was recorded with an elastic HR belt (Polar Electro Ltd., Kempele, Finland). The subjects were reminded that they could stop the test at any time they wanted. The test was performed on a bicycle ergometer (Monark Exercise AB, Vansbro, Sweden). After filling in subjects' information (gender, age, height, weight, physical activity level (0-7)), the computer software gives a non-exercise estimate of the subject's $\mathrm{VO}_{2 \max }$ and based on this information suggests loads for each stage of the test. The suggested loads were predominantly used or possibly changed during the test, if the load was too light or heavy. The subjects were asked to keep pedaling at $60 \mathrm{rpm}$ throughout the test so that the load and power could easily be determined. The test consisted of a warm-up period ( $2 \mathrm{~min}$ ), 3 times 4-min stages of increasing load, and a cool-down period. Heart rate was recorded during the last $30 \mathrm{~s}$ of each stage.

\section{Heart rate variability recordings and analysis}

Heart rate variability (HRV) recordings were obtained on 4 consecutive days (total $96 \mathrm{~h}$ ), starting in the morning of the work shift ( 8 a.m.) and ending at the beginning of the next shift ( 8 a.m.). The electrodes were not removed during the recording period and the wires were disconnected only when taking a shower or going to the sauna. The sampling rate of $1000 \mathrm{~Hz}$ was used in HRV recordings (Bodyguard, Firstbeat Technologies Ltd., Jyväskylä, Finland), and electrocardiogram (ECG) electrodes were on the chest (Kendall/Tyco ARBO H92). The daily habits (e.g., physical activity, alcohol consumption, food intake) of the subjects were not limited in any way during the HRV measurement period. The idea was to get a picture of a regular shift and a normal resting period between shifts among the rescue workers.

While wearing the HRV recorder, subjects kept a diary on their daily activities. Work shifts, naps, sleeping periods, and physical activity periods were written down with exact times. In addition, an estimation of how long it took the subject to fall asleep at bedtime was recorded.

In the analysis, the HRV data was firstly split into 24-h sections. Also, from each of these 24-h sections, a 2.5-h night HRV recording was used in the analysis that had started 30 min after going to bed. This time period enabled to maximize the utilization of the recorded HRV data because some of the firefighters only slept short periods at a time during their work shift. The ECG data was analyzed with special software for HRV analyses (Firstbeat Health 3.1, Firstbeat Technologies Ltd., Jyväskylä, Finland). The HRV indices were calculated second-bysecond using the short-time Fourier Transform method (STFT), and HR- and HRV-derived variables that 
described respiration rate and oxygen consumption using the neural network modeling of data [3].

After this modeling of data, the software identifies exercise, stress, and recovery states. The software automatically detects and replaces artifacts. After the analysis with the software, data was transferred to Microsoft Excel and remaining artifacts were removed by visual inspection. Data was used for the further analysis if $\geq 80 \%$ of the data was left after removal of the artifacts. This means that from the 24 -h recording, maximally $4 \mathrm{~h}$ and 48 min were removed. The following HRV parameters elicited from the data were analyzed: standard deviation of normal-to-normal intervals (SDNN), root mean square of successive differences (RMSSD), very low frequency power (VLF) $(0.003-0.04 \mathrm{~Hz})$, low frequency power (LFP) $(0.04-0.15 \mathrm{~Hz})$, high frequency power (HFP) $(0.15-0.40 \mathrm{~Hz})$, low to high frequency ratio $(\mathrm{LF} / \mathrm{HF})$, and total power (TP). The same software also computes stress and relaxation percentages for the recording period using the neural network modeling [21], and both of them were used in the later analysis.

\section{Cortisol measurements}

Salivary cortisol responses were used in this study for revealing stress and recovery processes in the body. However, only 12 out of 14 subjects were able to deliver all of the saliva samples due to technical reasons. Cortisol awakening response was measured from salivary samples, which were collected on 3 consecutive resting days, on the same rest days as HRV was recorded. Salivary samples were only collected after a longer period of sleep at night, and no samples were collected after naps. The subjects collected saliva samples $0 \mathrm{~min}, 15 \mathrm{~min}$, and $30 \mathrm{~min}$ after awakening according to the instructions on how to collect the saliva samples with a cotton pad. They were told to gently chew and roll the cotton tampon around in the mouth for $1 \mathrm{~min}$ and then to put it in the Salivette tube (Sarstedt Ltd., Rommelsdorf, Germany).
The subjects had stored the samples in refrigerators until all the samples were collected. When all the samples had been collected they were brought to the research facilities and were frozen at $-20^{\circ} \mathrm{C}$. After melting, the samples were centrifuged at $3500 \mathrm{rpm}$ for $10 \mathrm{~min}$. Chemiluminescent immunoassay method was used for the analysis of cortisol (Immulite 1000, Siemens, Llanberis, UK). Intra- and inter-assay variability of the assay was $11.5 \%$ and $15.4 \%$, respectively.

\section{Description of the work shift}

The subjects did shift work, which began at 8 a.m. Then they worked $24 \mathrm{~h}$ at a time followed by resting for $72 \mathrm{~h}$. The work shift was split into 2 12-h sections: $12 \mathrm{~h}$ of firefighting work and $12 \mathrm{~h}$ of paramedic work. In general, the $12 \mathrm{~h}$ of paramedic work was busier than $12 \mathrm{~h}$ of firefighting. From the detailed reports of work shift activities, it was seen that in the 12-h paramedic work shift, the subjects had alarms more frequently than in the 12-h firefighting shift. Most subjects had 1-2 firefighting-related activities during the $12 \mathrm{~h}$. Most of the subjects were able to take naps during their shift, and 10 subjects were also able to sleep longer periods ( $>2.5 \mathrm{~h}$ ) at night. Eight subjects were able to sleep $>4 \mathrm{~h}$ during their shift. In addition, most of the subjects exercised during their shift (11 out of 14). Riding a stationary bike and doing resistance training were the most popular modes of exercise.

\section{Ethics}

The study was approved by the Ethical Committee of the University of Jyväskylä, Finland.

\section{Statistics}

Statistical analyses were done with IBM SPSS Statistics for Windows 20.0 (IBM Corp., Armonk, NY, USA) and Microsoft Excel 2010. Values were expressed as means and standard errors (SE) or $95 \%$ confidence intervals (CI). Probability level of $\leq 0.05$ was set for statistically signifi- 
cant results. Generalized estimating equations (GEE) were used for the analysis of means (HR, HRV, cortisol), and the association between aerobic fitness and the HRV variables. Both 24-h and 2.5-h night recordings were used in the HRV analysis. Statistical analysis was done to reveal any association with the HRV variables and $\mathrm{VO}_{2 \max }$. The effect of time was also analyzed, as well as the combined effect of $\mathrm{VO}_{2 \max }$ and time. The values from each of the 3 resting days (or nights) were compared to the working day (or night) values.

\section{RESULTS}

\section{Changes in HRV over 4 days}

The Figure 1 shows that SDNN had increased gradually since the 24-h working day (mean value of $214 \mathrm{~ms}$ ), and this increase was statistically significant on the 2 nd rest day $(241 \mathrm{~ms})$ and $3 \mathrm{rd}$ rest day $(251 \mathrm{~ms})(\mathrm{p}<0.05$, $\mathrm{p}<0.001$, respectively). The low to high frequency ratio calculated over the 24-h period had decreased $(p<0.001)$ after the highest mean value of 2.11 on the working day (Figure 2). A significant decrease in $\mathrm{LF} / \mathrm{HF}$ ratio

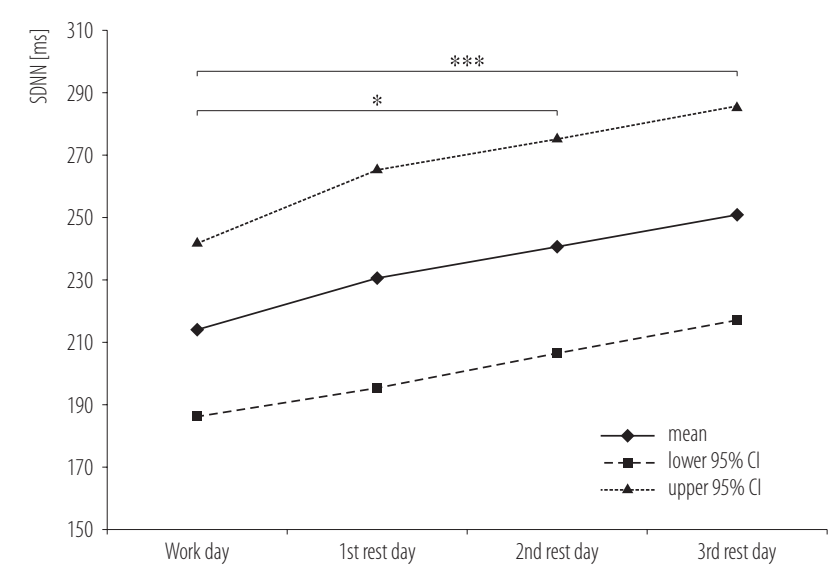

SDNN - standard deviation of normal-to-normal intervals;

$\mathrm{CI}$ - confidence interval.

* Statistically significant: $p<0.05$.

*** Statistically significant: $\mathrm{p}<0.001$.

Fig. 1. Mean $( \pm 95 \% \mathrm{CI}) \mathrm{SDNN}$ during $24 \mathrm{~h}$ recordings in the study of what kind of changes in autonomic control may be seen during work shift and its recovery period in rescuers $(\mathrm{N}=14)$

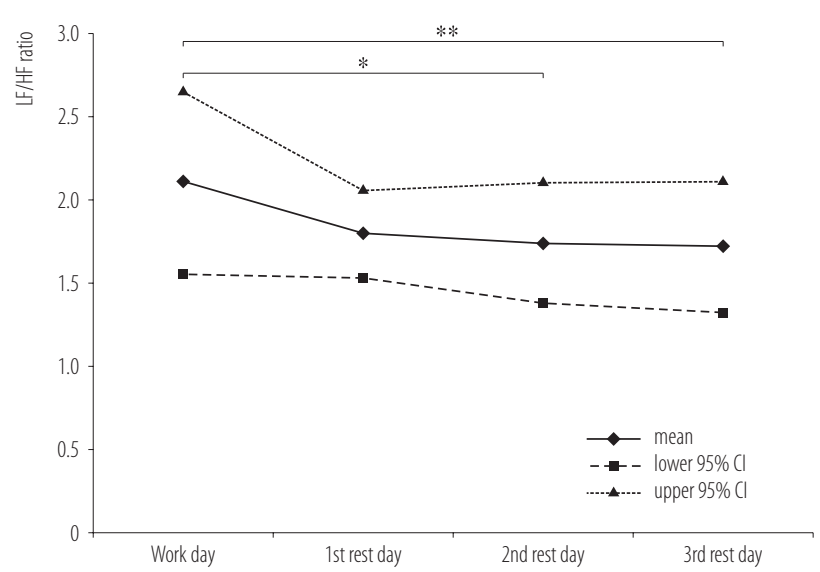

LF/HF - low to high frequency; CI - confidence interval.

* Statistically significant: $p<0.05$.

** Statistically significant: $\mathrm{p}<0.01$.

Fig. 2. Mean $( \pm 95 \% \mathrm{CI}) \mathrm{LF} / \mathrm{HF}$ ratio during $24 \mathrm{~h}$ recordings in the study of what kind of changes in autonomic control may be seen during work shift and its recovery period for rescuers $(\mathrm{N}=14)$

$(\mathrm{p}<0.05)$ was also observed on the 2 nd rest day and 3 rd rest day in comparison to the working day. Stress percentage also showed a statistically significant decrease in stress when comparing the working day value $(47.1 \%)$ to the 2 nd rest day value $(35.2 \%, \mathrm{p}<0.05)$.

\section{Association of aerobic fitness to HRV}

The Table 1 shows that the unit increase in $\mathrm{VO}_{2 \max }$ did not change RMSSD (night) ( $p>0.05$ ) but we observed a significant main effect of time $(\mathrm{p}<0.001)$. The difference between baseline (work night) and second followup measurement (2nd rest night) indicated an increase in the level of RMSSD ( $<<0.001)$. For all other time points, the time effect was negative and statistically nonsignificant. The change over time attributable to $\mathrm{VO}_{2 \max }$ (i.e., the interaction effect with time) was significant when comparing the work night and 2nd rest night $(\mathrm{p}<0.001)$. The unit increase in $\mathrm{VO}_{2 \max }$ did not change RMSSD (24 h) (Table 1). We again observed the significant main effect of time ( $p<0.001)$. An increase in the level of RMSSD was observed in the difference between the working day 
Table 1. Effect estimates, standard errors and p-values for generalized estimation equation models for RMSSD (night) and RMSSD $(24 \mathrm{~h})$ in the study of what kind of changes in autonomic control may be seen during work shift and its recovery period for rescuers $(\mathrm{N}=14)$

\begin{tabular}{|c|c|c|c|c|c|c|}
\hline \multirow{3}{*}{ Effect } & \multicolumn{6}{|c|}{ RMSSD } \\
\hline & \multicolumn{3}{|c|}{ night } & \multicolumn{3}{|c|}{$24 \mathrm{~h}$} \\
\hline & estimate & SE & $\mathrm{p}^{\mathrm{a}}$ & estimate & SE & $\mathrm{p}^{\mathrm{a}}$ \\
\hline $\mathrm{VO}_{2 \max }$ & 0.71 & 0.89 & 0.428 & 1.09 & 0.68 & 0.112 \\
\hline Time & & & $<0.001$ & & & $<0.001$ \\
\hline 1st rest vs. baseline & -14.65 & 11.96 & 0.221 & 43.11 & 12.36 & $<0.001$ \\
\hline 2nd rest vs. baseline & 37.22 & 8.81 & $<0.001$ & 0.73 & 15.09 & 0.961 \\
\hline 3rd rest vs. baseline & -17.19 & 24.16 & 0.477 & 34.59 & 17.23 & 0.045 \\
\hline Time $\times \mathrm{VO}_{2 \max }$ & & & $<0.001$ & & & $<0.001$ \\
\hline 1st rest vs. baseline & 0.14 & 0.20 & 0.493 & -0.85 & 0.21 & $<0.001$ \\
\hline 2nd rest vs. baseline & -0.82 & 0.13 & $<0.001$ & 0.12 & 0.29 & 0.682 \\
\hline 3rd rest vs. baseline & 0.25 & 0.44 & 0.568 & -0.69 & 0.30 & 0.021 \\
\hline
\end{tabular}

RMSDD - root mean square of successive differences. $\mathrm{VO}_{2 \max }$ - maximal oxygen uptake; $\mathrm{SE}$ - standard error.

${ }^{a}$ Total effect of Time and Time $\times \mathrm{VO}_{2 \max }$ is the type III effect.

and the 1st and 3rd rest days $(\mathrm{p}<0.001$ and $\mathrm{p}<0.05$, respectively). On the 2 nd rest day, the time effect was also positive but statistically non-significant. The change over time attributable to $\mathrm{VO}_{2 \max }$ was significant when comparing the work day and the 1st and 3rd rest days $(\mathrm{p}<0.001$, $\mathrm{p}<0.05$, respectively).

The Table 2 shows that the unit increase in $\mathrm{VO}_{2 \max }$ did not statistically change SDNN (night). The unit increase in $\mathrm{VO}_{2 \max }$ did not affect SDNN (24 h), either. We observed the significant $(\mathrm{p}<0.01)$ main effect of time in SDNN (24 h). No significant main effect of time was observed in SDNN (night). The difference between the baseline (working day) and the rest days indicated an increase in the level of SDNN (24 h), 3rd rest day having a significant effect ( $p<0.001$ ). Night recordings showed a non-significant change in the average level of SDNN in rest nights. The interaction effect of $\mathrm{VO}_{2 \max }$ and time was significant when comparing the work day and $3 r d$ rest day $(p<0.05)$.
The significant main effect of time was observed in both night and $24 \mathrm{~h}$ recordings ( $\mathrm{p}<0.01$ and $\mathrm{p}<0.05$, respectively) of LF/HF ratio (Table 3). There was a non-significant decrease in LF/HF ratio (both night and $24 \mathrm{~h}$ recordings) with the unit increase in $\mathrm{VO}_{2 \max }$. The difference between baseline and the rest nights indicated a decrease in $\mathrm{LF} / \mathrm{HF}$ ratio, the 2 nd rest night being significantly lower $(\mathrm{p}<0.01)$. In addition, the difference between working $24 \mathrm{~h}$ and resting $24 \mathrm{~h}$ indicated a decrease in LF/HF ratio, 3rd resting day being significantly lower $(p<0.05)$. The combined effect of time and $\mathrm{VO}_{2 \max }$ showed a significant positive effect on 2 nd rest night and 3rd rest day ( $p<0.01$ and $p<0.05$, respectively).

\section{Cortisol awakening response (CAR)}

Cortisol values were at their lowest point at the first measurement ( $0 \mathrm{~min})$ and, thereafter, increased gradually on all days (Figure 3). Mean values of cortisol 
Table 2. Effect estimates, standard errors and p-values for generalized estimation equation models for SDNN (night) and SDNN $(24 \mathrm{~h})$ in the study of what kind of changes in autonomic control may be seen during work shift and its recovery period for rescuers $(\mathrm{N}=14)$

\begin{tabular}{|c|c|c|c|c|c|c|}
\hline \multirow{3}{*}{ Effect } & \multicolumn{6}{|c|}{ SDNN } \\
\hline & \multicolumn{3}{|c|}{ night } & \multicolumn{3}{|c|}{$24 \mathrm{~h}$} \\
\hline & estimate & SE & $\mathrm{p}^{\mathrm{a}}$ & estimate & SE & $\mathrm{p}^{\mathrm{a}}$ \\
\hline $\mathrm{VO}_{2 \max }$ & -0.58 & 1.23 & 0.635 & 1.95 & 1.45 & 0.180 \\
\hline Time & & & 0.712 & & & 0.006 \\
\hline 1st rest vs. baseline & -30.29 & 29.38 & 0.303 & 31.11 & 37.73 & 0.410 \\
\hline 2nd rest vs. baseline & -15.05 & 26.18 & 0.565 & 138.07 & 86.29 & 0.110 \\
\hline 3rd rest vs. baseline & -80.08 & 84.05 & 0.341 & 79.69 & 24.47 & 0.001 \\
\hline Time $\times \mathrm{VO}_{2 \max }$ & & & 0.388 & & & 0.053 \\
\hline 1st rest vs. baseline & 0.62 & 0.52 & 0.237 & -0.41 & 0.63 & 0.518 \\
\hline 2nd rest vs. baseline & 0.18 & 0.49 & 0.714 & -2.26 & 1.82 & 0.213 \\
\hline 3rd rest vs. baseline & 1.46 & 1.56 & 0.351 & -0.080 & 0.37 & 0.030 \\
\hline
\end{tabular}

SDNN - standard deviation of normal-to-normal intervals.

Other abbreviations as in Table 1.

a Total effect of Time and Time $\times \mathrm{VO}_{2 \max }$ is the type III effect.

Table 3. Effect estimates, standard errors and p-values for generalized estimation equation models for LF/HF ratio (night) and LF/HF ratio (24 h) in the study of what kind of changes in autonomic control may be seen during work shift and its recovery period for rescuers $(\mathrm{N}=14)$

\begin{tabular}{|c|c|c|c|c|c|c|}
\hline \multirow{3}{*}{ Effect } & \multicolumn{6}{|c|}{$\mathrm{LF} / \mathrm{HF}$ ratio } \\
\hline & \multicolumn{3}{|c|}{ night } & \multicolumn{3}{|c|}{$24 \mathrm{~h}$} \\
\hline & estimate & SE & $\mathrm{p}^{\mathrm{a}}$ & estimate & SE & $\mathrm{p}^{\mathrm{a}}$ \\
\hline $\mathrm{VO}_{2 \max }$ & -0.02 & 0.01 & 0.201 & -0.17 & 0.18 & 0.340 \\
\hline Time & & & 0.009 & & & 0.021 \\
\hline 1st rest vs. baseline & -0.39 & 0.40 & 0.324 & -1.04 & 0.65 & 0.108 \\
\hline 2nd rest vs. baseline & -0.87 & 0.31 & 0.005 & -0.21 & 0.78 & 0.787 \\
\hline 3rd rest vs. baseline & -0.70 & 0.58 & 0.231 & -1.12 & 0.47 & 0.018 \\
\hline Time $\times \mathrm{VO}_{2 \max }$ & & & 0.004 & & & 0.038 \\
\hline 1st rest vs. baseline & 0.01 & 0.01 & 0.351 & 0.18 & 0.12 & 0.142 \\
\hline 2nd rest vs. baseline & 0.02 & 0.01 & 0.008 & -0.06 & 0.18 & 0.731 \\
\hline 3rd rest vs. baseline & 0.01 & 0.01 & 0.304 & 0.21 & 0.10 & 0.049 \\
\hline
\end{tabular}

LF/HF - low to high frequency.

Other abbreviations as in Table 1.

a Total effect of Time and Time $\times \mathrm{VO}_{2 \max }$ is the type III effect. 


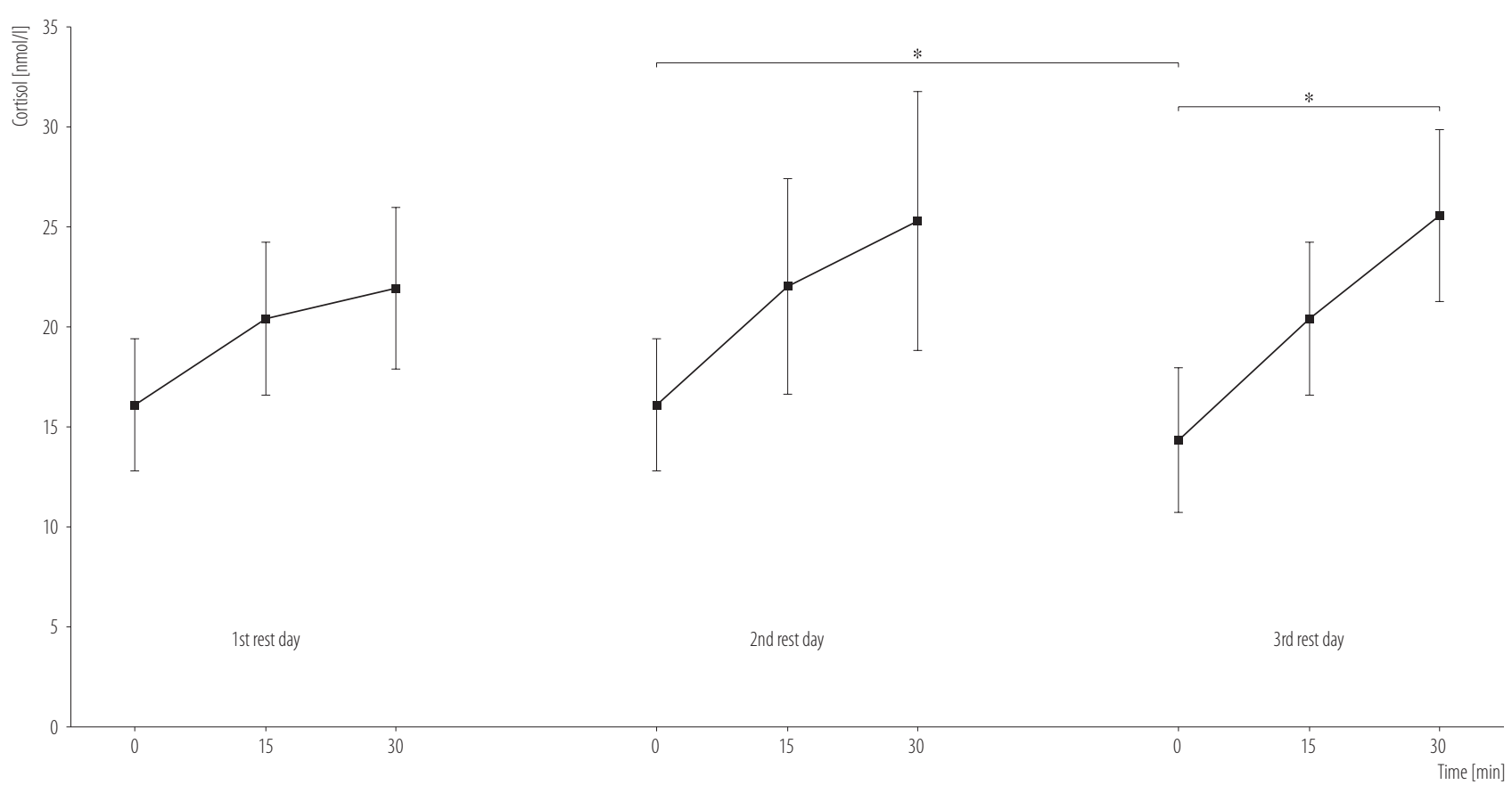

* Statistically significant: $\mathrm{p}<0.05$.

Fig. 3. Cortisol awakening response (CAR) over 3 days measured immediately ( $0 \mathrm{~min}), 15 \mathrm{~min}$ and $30 \mathrm{~min}$ after awakening in the study of what kind of changes in autonomic control may be seen during work shift and its recovery period for rescuers $(\mathrm{N}=14)$

(all 3 days combined) at $0 \mathrm{~min}, 15 \mathrm{~min}$, and $30 \mathrm{~min}$ were $15.5 \mathrm{nmol} / 1,21 \mathrm{nmol} / 1$, and $24.3 \mathrm{nmol} / 1$, respectively. Both 15 min and 30 min values of cortisol were significantly higher than mean cortisol at $0 \min (p<0.001, p<0.01$, respectively). The cortisol level on the day 2 at 0 min was significantly higher than at 0 min on the day $3(p<0.05)$. Thereafter, the cortisol levels increased significantly from 0 min to $30 \min (p<0.05)$.

\section{DISCUSSION}

\section{Recovery state after the work shift}

It was expected that measures reflecting overall HRV and parasympathetic influence on the heart would have increased with increasing recovery time. Standard deviation of normalto-normal intervals reflected the overall variability of $\mathrm{HR}$ and high variability reflected a well recovered state of the autonomic nervous system. Thus, it was no surprise to see an increase in the 24-h recordings of SDNN during the recovery period. This measure was the lowest during the work shift and increased thereafter, with significant increases on the 2nd and 3rd resting days. Therefore, these results support the hypothesis of increasing recovery with increasing time for rest.

The low to high frequency ratio decreased significantly on the 2 nd and 3 rd resting days from the working day value. This was expected, since a decrease in the ratio would have suggested a decrease in stress levels. This was further confirmed by the finding that stress percentage also decreased significantly after the working day. However, the decrease did not extend to the last resting day. This effect could be explained by the high levels of physical activity during the resting period.

\section{Aerobic fitness and recovery}

Since endurance exercise improves autonomic HR control at rest and autonomic HR response to endurance exercise [15], it has been hypothesized that good aerobic fitness 
levels would increase HRV and thus, may enhance recovery processes for rescuers. When interpreting the results it has to be noted that, although the significant main effect of time is related to an increase in RMSSD, this increase is, however, reduced for subjects with better values of $\mathrm{VO}_{2 \max }$. Thus, the increase in RMSSD leveled off with increasing levels of $\mathrm{VO}_{2 \max }$. This effect was also seen in other measures of HRV, such as SDNN (24 h). Based on these results, good aerobic fitness did not associate with HRV, although increased RMSSD and SDNN were measures reflecting enhanced parasympathetic functioning of ANS.

Although this study has not looked at intervention effects of an exercise training program, previous literature shows that exercise training improves HRV and autonomic control of the heart [22,23]. Improved autonomic control of the heart, in turn, enhances recovery processes. Buch et al. [24] have reported that increased parasympathetic influence on the heart decreases the amount of work and oxygen consumption by the heart because of a reduction in resting heart rate (RHR) and myocardial contractility.

\section{Cortisol awakening response}

An expected increase in cortisol shortly after awakening (CAR) was clear on all 3 days of measurement. There was an increase in mean cortisol from immediately after awakening to $30 \mathrm{~min}$ after awakening, and this increase was statistically significant. In the literature [25], an increase of 50-160\% in cortisol has also been reported during the first $30 \mathrm{~min}$ after awakening. Cortisol measured immediately after awakening was significantly higher on the resting day 2 than on the resting day 3. As cortisol reflects stress in the body, these results show that stress levels measured from hormonal secretions do not recover until on the last rest day.

There seems to be an attenuated response in CAR in the 1st resting morning, which is the next morning after the work shift. Many studies have been conducted on the changes in CAR in response to different stressors (work stress, posttraumatic stress disorder (PTSD), acute stressors) but the results have been inconsistent. Some studies have shown an augmented CAR response [26,27], while others report an attenuated response [28,29] in relation to stress. Chida and Steptoe [30] have reported in their meta-analysis of 147 studies that CAR is positively associated with stressors like work and general life stress, and that it is negatively associated with fatigue, burnout, and exhaustion.

Clow et al. [25] have studied the methodological issues with CAR measurement and analysis and reported that "it remains unclear whether positive affect and good health are consistently associated with larger or smaller awakening responses." Because of the discrepancy in the literature, it is hard to draw definite conclusions from the results of the CAR measurement in this study. Also, since the results from HRV measurements are partly inconsistent, it is difficult to relate the CAR findings to the autonomic nervous system recovery state measured with HRV. Both biomarkers might, however, might be useful in the assessment of work-related stress [31].

To sum up, some statistically significant changes were seen in the HRV variables, but not all of them supported the original hypotheses. When looking at the leisure time activities of these rescuers it was clear that most of the subjects were physically very active on their off-days. It seems reasonable to suggest that the large amount of physical exertion during days off might have affected the results, since physical exertion decreases HRV $[14,15]$. This exercise effect, paired with a low number of subjects, might have blunted some of the recovery effects so that some statistically significant results were not found.

These results support the view that the integrated model of perceived and physiological measurements could be beneficial to assess cardiovascular strain among firefighters with long work shifts [32]. Maybe extremely hard physical exertion could be avoided before the work shift so that recovery before the upcoming shift would be optimized. 
The night-time recordings seem to conflict with the 24-h recordings. Lifestyle factors, such as alcohol consumption, might attenuate physiological recovery also among healthy and fit firefighters. It is hard to speculate other reasons for this discrepancy between the 24-h and night recordings of HRV. In conclusion, rescuers should pay attention to sufficient recovery before the next work shift. It is quite clear that hard physical exertion and alcohol consumption should be avoided before the work shift so that recovery before the upcoming shift would be optimized.

\section{Limitations of the study}

It has to be noted that the subjects were not randomly sampled, and thus the subjects participating in the study may not be a perfect representative sample of all rescuers in Finland. Another issue in regard to limitations of the study is that there has been no control group. Because of the difficulty in comparing the work of rescuers to other occupations, it has been decided that no control group would be used in this study. Furthermore, no information from the diaries of the firefighters was included in the analyses, and thus only $\mathrm{VO}_{2 \max }$ and time (and their interaction) were considered as covariates in the analyses. Some of the participants were physically very active during the recording period. This was not unusual for them but physical activity had an effect on HR and HRV. However, the purpose of the study was to investigate stress and recovery markers during normal life and, therefore, this was why physical activity levels were not controlled. Some of the results might have been affected by outliers due to the small sample size.

\section{CONCLUSIONS}

It has been hypothesized that parasympathetic influence on the heart would increase with increasing recovery time. Some of the HRV indices have shown expected results such as stress percentage decreased after the work shift. As stated earlier, it has generally been agreed that exercise modulates the cardiac autonomic control by decreasing sympathetic influence and increasing parasympathetic tone of the heart.

\section{ACKNOWLEDGMENTS}

The authors thank Dr. Pirjo Rintala and Dr. Teemu Pullinen for their assistance during the measurements and Mr. Risto Puurtinen for analyzing saliva samples.

\section{REFERENCES}

1. Punakallio A, Lusa S, Luukkonen R, Airila A, Leino-Arjas P. Musculoskeletal pain and depressive symptoms as predictors of trajectories in work ability among Finnish firefighters at 13-year follow-up. J Occup Environ Med. 2014;56(4):367-75, https://doi.org/10.1097/JOM.0000000000000139.

2. Punakallio A, Lindholm H, Luukkonen R, Lusa S. Lifestyle factors predicting changes in aerobic capacity of aging firefighters at 3- and 13-year follow-ups. J Occup Environ Med. 2012;54(9):1133-41, https://doi.org/10.1097/JOM. 0b013e3182554b11.

3. Kinnunen M-L, Rusko H, Feldt T, Kinnunen U, Juuti T, Myllymäki T, et al. Stress and relaxation based on heart rate variability: Associations with self-reported mental strain and differences between waking hours and sleep. In: Saarela K, Nygård C, Lusa S, editors. Promotion of Well-Being in Modern Society. Tampere: Pk-paino; 2006. p. 136-9.

4. Lundberg U. Stress hormones in health and illness: The roles of work and gender. Psychoneuroendocrinology. 2005;30(10): 1017-21, https://doi.org/10.1016/j.psyneuen.2005.03.014.

5. Barger L, Lockley S, Rajaratnam S, Landrigan C. Neurobehavioral, health, and safety consequences associated with shift work in safety-sensitive professions. Curr Neurol Neurosci Rep. 2009;9(2):155-64, https://doi.org/10.1007/s11910-009-0024-7.

6. Folkard S, Tucker P. Shift work, safety and productivity. Occup Med. 2003;53:95-101, https://doi.org/10.1093/occmed/kqg047.

7. Harrington J. Health effects of shift work and extended hours of work. J Occup Environ Med. 2001;58:68-72, https://doi. org/10.1136/oem.58.1.68. 
8. Åkerstedt T. Shift work and disturbed sleep/wakefulness. Occup Med. 2003;53:89-94, https://doi.org/10.1093/occmed/ kqg046.

9. Lusa S, Kaikkonen P, Paunila J, Rajala M-R, Saarinen K, Lindhom $\mathrm{H}$. [Evaluation of loading and recovery of rescue personnel] [Internet]. Tampere: Finnish Institute of Occupational Health; 2010. Available from: http:/www.pelastusopisto.fi/download/38487_TTT_MALLI_080110.pdf. Finnish.

10. Bos J, Mol E, Visser B, Frings-Dresen M. The physical demands upon (Dutch) fire-fighters in relation to the maximum acceptable energetic workload. Ergonomics. 2004;47(4): 446-60, https://doi.org/10.1080/00140130310001643283.

11. Barr D, Gregson W, Reilly T. The thermal ergonomics of firefighting reviewed. Appl Ergon. 2010;41(1):161-72, https://doi.org/10.1016/j.apergo.2009.07.001.

12. Angerer P, Kadlez-Gebhardt S, Delius M, Raluca P, Nowak D. Comparison of cardiocirculatory and thermal strain of male firefighters during fire suppression to exercise stress test and aerobic exercise testing. Am J Cardiol. 2008;102(11): 1551-6, https://doi.org/10.1016/j.amjcard.2008.07.052.

13. Carter J, Banister E, Blaber A. Effect of endurance exercise on autonomic control of heart rate. Sports Med. 2003;33(1): 33-46, https://doi.org/10.2165/00007256-200333010-00003.

14. Hynynen E. Heart rate variability in acute and chronic stress. With special reference to nocturnal sleep and acute challenges after awakening [dissertation]. Jyväskylä: University of Jyväskylä; 2011.

15. Martinmäki K. Transient changes in heart rate variability in response to orthostatic task, endurance exercise and training: With special reference to autonomic blockades and time-frequency analysis [dissertation]. Jyväskylä: University of Jyväskylä; 2009.

16. Nicolini P, Ciulla M, Asmundis C, Magrini F, Brugada P. The prognostic value of heart rate variability in the elderly, changing the perspective: From sympathovagal balance to chaos theory. Pacing Clin Electrophysiol. 2012;35(5):621-37, https://doi.org/10.1111/j.1540-8159.2012.03335.x.
17. Huovinen J, Tulppo M, Nissilä J, Linnamo V, Häkkinen K, Kyröläinen H. Relationship between heart rate variability and the serum testosterone-to-cortisol ratio during military service. Eur J Sport Sci. 2009;9(5):277-84, https://doi. org/10.1080/17461390902874040.

18. Aubert A, Seps B, Beckers F. Heart rate variability in athletes. Sports Med. 2003;33(12):889-919, https://doi.org/ 10.2165/00007256-200333120-00003.

19. Malfatto G, Facchini M, Sala L, Branzi G, Bragato R, Leonetti G. Effects of cardiac rehabilitation and beta-blocker therapy on heart rate variability after first acute myocardial infarction. Am J Cardiol. 1998;81(7):834-40, https://doi.org/ 10.1016/S0002-9149(98)00021-6.

20. Keskinen K, Häkkinen K, Kallinen M. [Manual of fitness testing]. Tampere: Tammer-Paino Oy; 2004. p. 86-8. Finnish.

21. Myllymäki T, Rusko H, Syväoja H, Juuti T, Kinnunen ML, Kyröläinen H. Effects of exercise intensity and duration on nocturnal heart rate variability and sleep quality. Eur J Appl Physiol. 2012;112(3):801-9, https://doi.org/10.1007/s00421011-2034-9.

22. Hautala AJ, Mäkikallio TH, Kiviniemi A, Laukkanen RT, Nissilä S, Huikuri HV, et al. Cardiovascular autonomic function correlates with the response to aerobic training in healthy sedentary subjects. Am J Physiol Heart Circ Physiol. 2003;285(4): H1747-H1752, https://doi.org/10.1152/ajpheart.00202.2003.

23. Nummela A, Hynynen E, Kaikkonen P, Rusko H. Endurance performance and nocturnal HRV indices. Int J Sports Med. 2010;31:154-9, https://doi.org/10.1055/s-0029-1243221.

24. Buch A, Coote J, Townend J. Mortality, cardiac vagal control and physical training - what's the link? Exp Physiol. 2002;87(4):423-35,https://doi.org/10.1111/j.1469-445X.2002. tb00055.x.

25. Clow A, Thorn L, Evans P, Hucklebridge F. The awakening cortisol response: Methodological issues and significance. Stress. 2004;7(1):29-37, https://doi.org/10.1080/1025389041 0001667205.

26. Karlson B, Eek F, Hansen Å, Garde A, Ørbæk P. Cortisol variability and self-reports in the measurement of 
work-related stress. Stress Health. 2011;27(2):11-24, https:// doi.org/10.1002/smi.1330.

27. Schulz P, Kirschbaum C, Prübner J, Hellhammer D. Increased free cortisol secretion after awakening in chronically stressed individuals due to work overload. Stress Med. 1998;14(2):91-8, https://doi.org/10.1002/(SICI)10991700(199804)14:2<91::AID-SMI765>3.0.CO;2-S.

28. Lauc G, Zvonar K, Vukšic-Mihaljevic Z, Flögel M. Postawakening changes in salivary cortisol in veterans with and without PTSD. Stress Health. 2004;20(2):99-102, https:// doi.org/10.1002/smi.1001.

29. Sjögren E, Leanderson P, Kristenson M. Diurnal saliva cortisol levels and relations to psychosocial factors in a population sample of middle-aged Swedish men and women. Int
J Behav Med. 2006;13(3):193-200, https://doi.org/10.1207/ s15327558ijbm1303_2.

30. Chida Y, Steptoe A. Cortisol awakening response and psychosocial factors: A systematic review and meta-analysis. Biol Psychol. 2009;80(3):265-78, https://doi.org/10.1016/j.bio psycho.2008.10.004.

31. Chandola T, Heraclides A, Kumari M. Psychophysiological biomarkers of workplace stressors. Neurosci Biobehav Rev. 2010;35(1):51-7, https://doi.org/10.1016/j.neubiorev.20 09.11.005.

32. Choi B, Schnall PL, Dobson M, Garcia-Rivas J, Kim HR, Zaldivar F, et al. Very long (> 48 hours) shifts and cardiovascular strain in firefighters: A theoretical framework. Ann Occup Environ Med. 2014;26(1):5, https://doi.org/10.1186/2052-4374-26-5.

This work is available in Open Access model and licensed under a Creative Commons Attribution-NonCommercial 3.0 Poland License - http://creativecommons.org/ licenses/by-nc/3.0/pl/deed.en. 